DIVISION OF THE HUMANITIES AND SOCIAL SCIENCES

CALIFORNIA INSTITUTE OF TECHNOLOGY

PASADENA, CALIFORNIA 91125

BIDDERS' CHOICE AUCTIONS: RAISING REVENUES THROUGH THE RIGHT TO CHOOSE

Jacob K. Goeree

University of Amsterdam

Charles R. Plott

California Institute of Technology

John Wooders

University of Arizona

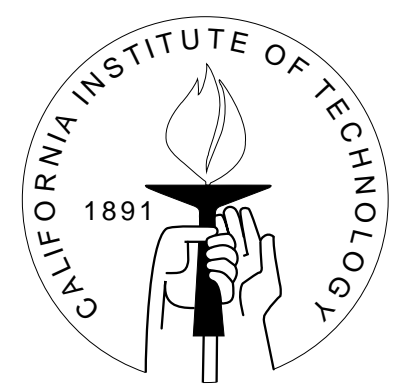

SOCIAL SCIENCE WORKING PAPER 1181

August 2003 


\title{
Bidders' Choice Auctions: Raising Revenues Through the Right to Choose ${ }^{1}$
}

\author{
Jacob K. Goeree, Charles R. Plott, and John Wooders ${ }^{2}$
}

August 2003

\begin{abstract}
Sales of multiple real-estate properties are often conducted via a sequence of ascending auctions, giving the winner at each stage the right to choose one of the available lots. We show that when bidders are risk averse, such "bidders' choice" auctions raise more revenues than standard simultaneous or sequential ascending auctions. We also report the results of laboratory experiments to investigate the effectiveness of bidders' choice auctions vis-a-vis the simultaneous ascending auction. The revenue-superiority of the bidders' choice auction is corroborated by the experimental data. Finally, we compare observed bidding behavior in the experiments with theoretically predicted bids to estimate a common risk aversion parameter from the data.
\end{abstract}

\footnotetext{
${ }^{1}$ We are grateful to Roberto Burguet for very helpful suggestions, and to Larry Ausubel, Tim Cason, and participants at the European Economic Association Meetings in Stockholm (August, 2003) for comments. We acknowledge financial support from the Alfred P. Sloan Foundation, the National Science Foundation, and the Caltech Laboratory for Experimental Economics and Political Science.

${ }^{2}$ Goeree: CREED, Department of Economics, University of Amsterdam, Roetersstraat 11, 1018 WB Amsterdam, The Netherlands. Plott: Division of Humanities and Social Sciences, California Institute of Technology, Mail code 228-77, Pasadena, CA 91125, USA. Wooders: Department of Economics, University of Arizona, 401 McClelland Hall, Tucson, AZ 85721, USA.
} 


\title{
1. Introduction
}

In its glossary of auction terms, the National Association of Realtors defines a bidders' choice auction as: ${ }^{1}$

\begin{abstract}
"A method of sale whereby the successful high bidder wins the right to choose a property (or properties) from a grouping of similar or like-kind properties. After the high bidder's selection, the property is deleted from the group, and the second round of bidding commences, with the high bidder in round two choosing a property, which is then deleted from the group and so on, until all properties are sold."
\end{abstract}

According to the web-site of another real-estate auctioneer, "this type of bidding is very popular when selling building lots, time-shares, and condominiums," ${ }^{2}$ see also Ashenfelter and Genesove (1992). In this paper, we investigate why sellers may wish to employ bidders' choice or "right-to-choose" auctions. The format we consider is the ascending right to choose (A-RTC) auction, which is commonly employed in the sale of real estate. The A-RTC auction has several stages of ascending bid auctions, with the high bidder at each stage winning the right to choose one item from the set of remaining items.

One interesting feature of the A-RTC auction is that it can create competition between bidders who are interested in different items for sale. Consider, for example, the case with two bidders and two items. Suppose each bidder is interested in one item only, and both are equally likely to prefer either item. When a standard simultaneous ascending (SA) auction is conducted the seller's revenue is zero when bidders prefer different items, which occurs with probability one-half. In contrast, in the first-stage of the A-RTC auction there is always competition since bidders, who do not know their rival's preference, run the risk that their preferred item is taken by the first-stage winner. The seller's revenue from an A-RTC auction is therefore strictly positive even when bidders turn out to prefer different items ex post.

The ability of the A-RTC auction to create competition between bidders interested in different items does not imply, however, that its expected revenue exceeds that of the SA auction. In fact, in those cases where bidders prefer the same item, they bid more aggressively in the SA auction since there is no chance of winning their preferred item in a later stage. We show below that, on average, both formats yield the same revenue when bidders are risk

\footnotetext{
${ }^{1}$ See http://www.aaauctionservice.com/glossery_files/glossery.htm

${ }^{2}$ See http://www.paxauctions.com/buyers/auction_types.html.
} 
neutral. Hence, the widespread use of bidders' choice auctions to sell different real-estate properties, for instance, remains unexplained when bidders and seller are risk neutral.

However, the seller's revenue from an A-RTC auction may exceed that of a SA auction when bidders are risk averse. Burguet (1999) makes this point nicely with the following example. Suppose that in the two-bidder example above, bidders' values are 1 for the preferred item and 0 for the other item. If the items are sold in the SA auction, the seller's revenue is 1 if both bidders prefer the same item and is zero otherwise. The seller's expected revenue is therefore $\frac{1}{2}$ independent of bidders' risk attitudes. Now consider the first stage of an A-RTC auction. The first bidder to drop out will win the second auction at a price of zero, and therefore obtains an expected payoff of $\frac{1}{2} u(1)+\frac{1}{2} u(0)$. Hence, a bidder will remain in the first stage auction until the bid reaches the price $R$ which makes her indifferent between winning the first stage at price $R$ or dropping out, i.e., until

$$
u(1-R)=\frac{1}{2} u(1)+\frac{1}{2} u(0)
$$

Since the second-stage revenue is zero, the total revenue of the A-RTC auction is $R$. It is straightforward to verify that $R$ is greater than $\frac{1}{2}$ when $u(\cdot)$ is concave, i.e., when bidders are risk averse.

Below we report the results of an experiment in which four bidders compete for two items in a SA or A-RTC auction. Bidders were equally likely to prefer either item, as in the example above. Our experimental results show that, consistent with the theoretical predictions for risk-averse bidders, the A-RTC generates significantly more revenue than a SA auction. From the data we estimate a common coefficient of constant relative risk aversion and find that it is $r=0.61$. With this coefficient of risk aversion, the theoretical model of the A-RTC auctions explains the data well. In particular, the empirical distribution of seller revenues obtained in our experiment closely lines up with the distribution of seller revenue predicted by the theory.

\section{RELATED LiterATURE}

Burguet $(1999,2002)$ studies the A-RTC auction when each bidder's value for the two items can be summarized by a single parameter. Burguet (1999) shows that the A-RTC auction raises more revenue than the SA auction for general concave utility functions. Burguet (2002) identifies the seller's optimal auction when bidders are risk neutral. He also shows that the ascending right to choose auction in which the seller doesn't disclose which item is 
sold at the first stage raises more revenue than the conventional A-RTC auction. Finally, Burguet (2002) demonstrates that prices decline in successive stages of the A-RTC auction (see also Gale and Hausch, 1994), as observed empirically (Ashenfelter and Genesove, 1992).

Meneze and Monteiro (1998) characterize equilibrium in so called "pooled" auctions. In these auctions $n$ bidders simultaneously submit sealed bids. The highest bidder first chooses one of the $k$ (possibly different) items, the second highest bidder then chooses one item from the remaining $k-1$ items, and so on. Each of the $k$ winners pay their own bid. Salmon and Iachini (2003) experimentally compare pooled auctions to simultaneous ascending auctions. They find that bids are above the level predicted by the risk-neutral bidding model. Indeed, bids are so high that subjects, on average, earn losses.

\section{Design of the Experiment}

We conducted two treatments as shown by the leftmost column of Table 1. We compared the simultaneous ascending (SA) auction with the ascending right-to-choose (A-RTC) format. The experiments were conducted at Caltech where subjects were recruited, 8 at a time, for an experiment lasting 30 periods. There were 3 groups of 8 subjects in total and each group was divided into two groups of 4 bidders. ${ }^{3}$

The first group of 8 subjects participated in 15 periods of the A-RTC auction, followed by fifteen periods with a different auction format. ${ }^{4}$ The order was reversed for the second group of 8 subjects. A final group of 8 subjects, divided into two groups of 4 bidders, participated in 30 periods of the SA auction. Bidders' values were randomly determined once (as described below) for each of the thirty periods. This same set of values was used for each group of four bidders in both treatments, so that comparisons between auction institutions are direct. Written instructions were distributed and then read out loud to the subjects. The remainder of the experiment was computerized.

In each period of the experiment, two items, $A$ and $B$, were auctioned among four bidders. The value each bidder assigned to each object was determined as follows. With probability one-half item $A$ was designated as her "preferred item" and with probability one-half item $B$ was designated as her "preferred item". A bidder's value for the preferred item was uniformly

\footnotetext{
${ }^{3}$ The composition of the group was fixed over the course of the experiment, but to avoid repeated game effects subjects were not informed of this fact.

${ }^{4}$ The data from this part of the experiment are not relevant for this paper.
} 


\begin{tabular}{|c|c|c|c|c|c|c|}
\hline \hline & $\begin{array}{c}\text { Number } \\
\text { of } \\
\text { Sessions }\end{array}$ & $\begin{array}{c}\text { Number } \\
\text { of } \\
\text { Subjects }\end{array}$ & $\begin{array}{c}\text { Number } \\
\text { of } \\
\text { Periods }\end{array}$ & $\begin{array}{c}\text { Bidders } \\
\text { per } \\
\text { Group }\end{array}$ & $\begin{array}{c}\text { Value } \\
\text { Preferred } \\
\text { Item }\end{array}$ & $\begin{array}{c}\text { Value } \\
\text { Inferior } \\
\text { Item }\end{array}$ \\
\hline SA & 1 & 8 & 30 & 4 & $U[20,920]$ & 20 \\
\hline A-RTC & 2 & 16 & 15 & 4 & $U[20,920]$ & 20 \\
\hline \hline
\end{tabular}

Table 1: Experimental Design.

distributed between 20 and 920 points and her value for the "inferior" item was 20 points (see the final two columns in Table 1). Which item a bidder preferred, and her value for the preferred item, was independent across bidders and across periods. When a bidder won an item, she earned a number of points equal to her value for the item minus her bid. ${ }^{5}$ At the end of the experiment points were converted to dollars at a rate of 300 points $=\$ 1$. The experiments lasted between 1.5 and 2 hours and subjects made about $\$ 20$ on average.

In the SA auction, the items were simultaneously sold in two ascending bid auctions. A bidder could bid on at most one item at a time, i.e., she could not bid on an item if she was the current high bidder on the other item. A bidder's computer screen displayed a clock which counted down to zero and also displayed, for each item, the current high bid and the ID of the current high bidder. Whenever a new bid was submitted on either item that exceeded the current high bid on that item, the clock was reset. When the clock counted down all the way to zero, the current high bidder for each item won the item and paid the winning bid.

In the A-RTC auction, two ascending auctions were run sequentially, with a clock counting down to zero in both stages. The clock was reset whenever a new bid was submitted that exceeded the current high bid. When the clock counted down all the way to zero in the first auction, the current high bidder won the right to choose either item $A$ or $B$ and had to pay her bid. After the winner selected an item, the other bidders observed which item was chosen and the remaining item was sold by an ascending auction.

\footnotetext{
${ }^{5} \mathrm{~A}$ bidder who didn't win either item received an "outside option" payoff of 80 points. The value distribution of $U[20,920]$ followed from the outside option combined with values drawn from $U[100,1000]$.
} 


\section{Theoretical Background}

Our theoretical analysis closely follows Burguet (1999). Bidder $i$ 's type is given by $\left(\theta_{i}, v_{i}\right)$, where $\theta_{i} \in\{A, B\}$ indicates the item bidder $i$ prefers and $v_{i}$ denotes her private value for the preferred item. Bidders' values are identically and independently distributed: the value for the preferred item is assumed to be uniformly distributed on $[\underline{v}, \bar{v}]$ and the value for the inferior item is $\underline{v}$. Bidders can acquire at most one item. All bidders have a common utility function $u$. When bidder $i$ wins an item of value $v$ at price $p$ then her utility is given by $u(v-p)$ where $u(0)=0, u^{\prime}(\cdot)>0$, and $u^{\prime \prime}(\cdot) \leq 0$, i.e. we assume bidders are (weakly) risk averse.

The SA Auction: The simultaneous ascending auction is the simplest format to analyze since risk aversion plays no role. It is an equilibrium strategy to bid on the item that yields the highest profit as long as this profit is positive. Hence the bidder with the overall highest value wins her preferred item, and the other item goes to the bidder with the highest value for that item. It is straightforward to determine the resulting expected revenue: ${ }^{6}$

$$
R_{S A}=\frac{57}{40} \underline{v}+\frac{23}{40} \bar{v}
$$

The A-RTC Auction: Equilibrium in the ascending right-to-choose auction is derived using a backward induction argument. The second-stage auction is a standard English auction for the one remaining item, and it is a dominant strategy to bid up to one's value. Note that risk aversion plays no role in the second stage, and that there is always some bidding activity since the values of the three remaining bidders for the item left are at least $\underline{v}>0$. Expected second-stage revenues are easily computed as $\frac{17}{20} \underline{v}+\frac{3}{20} \bar{v}^{7}$

The symmetric equilibrium bidding functions of the first stage are defined recursively. We assume that bidders observe when others drop out and that exit is irrevocable. Consider

\footnotetext{
${ }^{6}$ There is a $\frac{1}{8}$ chance that all four bidders prefer the same item in which case expected revenue is $\left(\frac{2}{5} \underline{v}+\right.$ $\left.\frac{3}{5} \bar{v}\right)+\underline{v}$, there is a $\frac{1}{2}$ chance that three bidders prefer the same item in which case expected revenue is $\left(\frac{1}{2} \underline{v}+\frac{1}{2} \bar{v}\right)+\underline{v}$, and there is a $\frac{3}{8}$ chance that two bidders prefer one item and the other two bidders prefer the other item in which case expected revenue is $2\left(\frac{2}{3} \underline{v}+\frac{1}{3} \bar{v}\right)$.

${ }^{7}$ With probability $\frac{1}{2}$ the item is preferred by at most one bidder in which case revenue is $\underline{v}$. With probability $\frac{1}{4}$ the second-stage price is determined by the lowest-value bidder in which case revenue is $(4 \underline{v}+\bar{v}) / 5$ and with probability $\frac{1}{4}$ the second-stage price is determined by the lowest-value bidder in which case revenue is $(3 \underline{v}+2 \bar{v}) / 5$.
} 
the case where all four bidders are still active. Unlike the standard ascending auction, a bidder will not bid all the way up to her value. The reason is that her profit vanishes when the price level approaches her value and she strictly prefers dropping out and taking her chances in the second stage auction. To derive second-stage expected payoffs, note that the first bidder to drop out can only make a positive profit if all her rivals prefer the other item, which happens with probability $\frac{1}{8}$. So, for a bidder whose value for her preferred item is $v$, the utility of participating in the second-stage auction is 0 with probability $\frac{7}{8}$ and $u(v-\underline{v})$ with probability $\frac{1}{8}$. The certainty equivalent of this lottery is $u^{(-1)}\left(\frac{1}{8} u(v-\underline{v})\right)$, where $u^{(-1)}(\cdot)$ denotes the inverse of the utility function. Hence it is optimal for this bidder to drop out of the first auction at price level

$$
B(v)=v-u^{(-1)}\left(\frac{1}{8} u(v-\underline{v})\right) .
$$

If the first bidder drops out at price level $p_{4}$, say, the remaining bidders infer her value to be $v_{4}=B^{-1}\left(p_{4}\right)$. The second-stage utility of the person who drops out next is therefore 0 with probability $\frac{3}{4}, u(v-\underline{v})$ with probability $\frac{1}{8}$, and $u\left(v-v_{4}\right)$ with probability $\frac{1}{8}$. Hence, it is optimal for the next bidder to drop out at the price level

$$
B\left(v \mid v_{4}\right)=v-u^{(-1)}\left(\frac{1}{8} u(v-\underline{v})+\frac{1}{8} u\left(v-v_{4}\right)\right) .
$$

Finally, after a second bidder drops out at price level $p_{3}$, the remaining two bidders infer this bidder's value to be $v_{3}=B^{-1}\left(p_{3} \mid v_{4}\right)$. Of the remaining two bidders, the second-stage utility of the next bidder to drop out is 0 with probability $\frac{1}{2}, u\left(v-v_{3}\right)$ with probability $\frac{1}{4}, u\left(v-v_{4}\right)$ with probability $\frac{1}{8}$, and $u(v-\underline{v})$ with probability $\frac{1}{8}$. She drops when the price reaches

$$
B\left(v \mid v_{3}, v_{4}\right)=v-u^{(-1)}\left(\frac{1}{8} u(v-\underline{v})+\frac{1}{8} u\left(v-v_{4}\right)+\frac{1}{4} u\left(v-v_{3}\right)\right) .
$$

From the above expressions it is straightforward to determine the effects of risk aversion. Following standard terminology, we say that bidders with utility function $u_{1}(\cdot)$ are more risk averse than bidders with utility function $u_{2}(\cdot)$ if $u_{1}$ is a strictly concave transformation of $u_{2}$, i.e., $u_{1}(\cdot)=g\left(u_{2}(\cdot)\right)$ with $g(0)=0$ and $g(\cdot)$ strictly concave. Write $B_{i}(v), B_{i}\left(v \mid v_{4}\right)$, and $B_{i}\left(v \mid v_{3}, v_{4}\right)$ for the bidding functions above where the utility function $u$ is replaced with $u_{i}$. We say more risk averse bidders bid more aggressively if $B_{1}(v)>B_{2}(v), B_{1}\left(v \mid v_{4}\right)>B_{2}\left(v \mid v_{4}\right)$, 
and $B_{1}\left(v \mid v_{3}, v_{4}\right)>B_{2}\left(v \mid v_{3}, v_{4}\right)$ for all $v>v_{3}>v_{4}>\underline{v}$.

Proposition 1. In the A-RTC auction, more risk averse bidders bid more aggressively.

Proof. By including a term $u(0)=0$, the three bidding functions above can be written as

$$
v-u^{(-1)}\left(\sum_{k=0}^{K} p_{k} u\left(x_{k}\right)\right)
$$

for $K=1,2,3$, where $\sum_{k=0}^{K} p_{k}=1 .^{8}$ Since $g^{(-1)}$ is strictly convex, Jensen's inequality yields

$$
u_{1}^{(-1)}\left(\sum_{k=0}^{K} p_{k} u_{1}\left(x_{k}\right)\right)=u_{2}^{(-1)}\left(g^{(-1)}\left(\sum_{k=0}^{K} p_{k} g\left(u_{2}\left(x_{k}\right)\right)\right)\right)<u_{2}^{(-1)}\left(\sum_{k=0}^{K} p_{k} u_{2}\left(x_{k}\right)\right) .
$$

Hence, more risk averse bidders bid more aggressively.

Q.E.D.

We next determine the effects of risk aversion on revenues. Let $Y_{k}$ denote the $k^{\text {th }}$ order statistic from four value draws. Total expected revenue of the A-RTC auction is given by

$$
R_{A R T C}=E_{Y_{2}, Y_{3}, Y_{4}}\left(B\left(Y_{2} \mid Y_{3}, Y_{4}\right)\right)+\frac{17}{20} \underline{v}+\frac{3}{20} \bar{v} .
$$

An easy corollary to Proposition 1 is that with risk averse bidders the A-RTC auction yields more revenue.

Proposition 2. The expected revenue of the A-RTC auction exceeds that of the $S A$ auction when bidders are risk averse. The formats are revenue equivalent when bidders are risk neutral.

Proof. In light of Proposition 1, the first claim follows from the second one since risk aversion has no effect in the SA auction while it raises bids in the A-RTC auction. When bidders are risk neutral, $u(x)=u^{(-1)}(x)=x$, so that $B\left(v \mid v_{3}, v_{4}\right)=\frac{1}{2} v+\frac{1}{8} \underline{v}+\frac{1}{8} v_{4}+\frac{1}{4} v_{3}$. A straightforward computation shows that $R_{A R T C}=\frac{57}{40} \underline{v}+\frac{23}{40} \bar{v}=R_{S A}$ in this case. Q.E.D.

In the next sections we report experimental evidence on the revenue generating properties of the SA and A-RTC auctions.

\footnotetext{
${ }^{8}$ Here $x_{0}=0, x_{1}=v-\underline{v}, x_{2}=v-v_{4}, x_{3}=v-v_{3}$, and $p_{1}=\frac{1}{8}, p_{2}=\frac{1}{8}, p_{3}=\frac{1}{4}, p_{0}=1-\sum_{k=1}^{K} p_{k}$ for $K=1,2,3$.
} 


\section{Results: Aggregate Data}

The first row of Table 2 gives the mean per-period observed revenue for each auction format. (Standard deviations are in parentheses.) The second row gives mean predicted revenue, conditional on the induced values actually used in the experiment, for risk-neutral bidders. Finally, the third row of the table shows predicted revenue for the risk aversion parameter estimated in Section 5. ${ }^{9}$ Note that observed revenues are in line with the theoretical results with risk averse bidding - the A-RTC auction generates more revenue than the SA. The standard deviation of revenues, however, is higher for the A-RTC auction. Figure 1 provides another way of looking at the revenues properties of the auction formats. The empirical c.d.f. of revenues in the A-RTC auction first-order stochastically dominates the same c.d.f. for the SA auction. Hence, a seller whose utility is increasing in revenue prefers the A-RTC auction to the SA auction.

\begin{tabular}{|c|c|c|}
\hline \hline & SA & A-RTC \\
\hline Observed Revenue: $R_{\text {obs }}$ & $579(294)$ & $691(341)$ \\
Risk Neutral Prediction: $R_{\text {pred }}^{R N}$ & $556(290)$ & $553(320)$ \\
Risk Averse Prediction: $R_{\text {pred }}^{R A}$ & $556(290)$ & $664(345)$ \\
\hline Efficiency & $100.0 \%$ & $98.4 \%$ \\
\hline Bidders' Profits: $\pi_{\text {bidders }}$ & $479(329)$ & $356(291)$ \\
\hline \hline
\end{tabular}

Table 2: Predicted and observed per-round revenues (top panel), observed efficiencies (middle panel), and observed bidders' profits (bottom panel). The numbers in parentheses give standard deviations.

We next discuss tests of whether the revenue differences between auctions are statistically significant. For each observation $i=1, \cdots, 60$ in the A-RTC auction, define $\delta_{i}^{A R T C}=R_{o b s, i}^{A R T C}-R_{\text {pred }, i}^{A R T C}$ to be the difference between the $i$-th observed revenue and the

\footnotetext{
${ }^{9}$ The estimation procedure is discussed in the next section. Note that for the SA auction, predicted revenue is the same whether bidders are risk neutral or risk averse.
} 


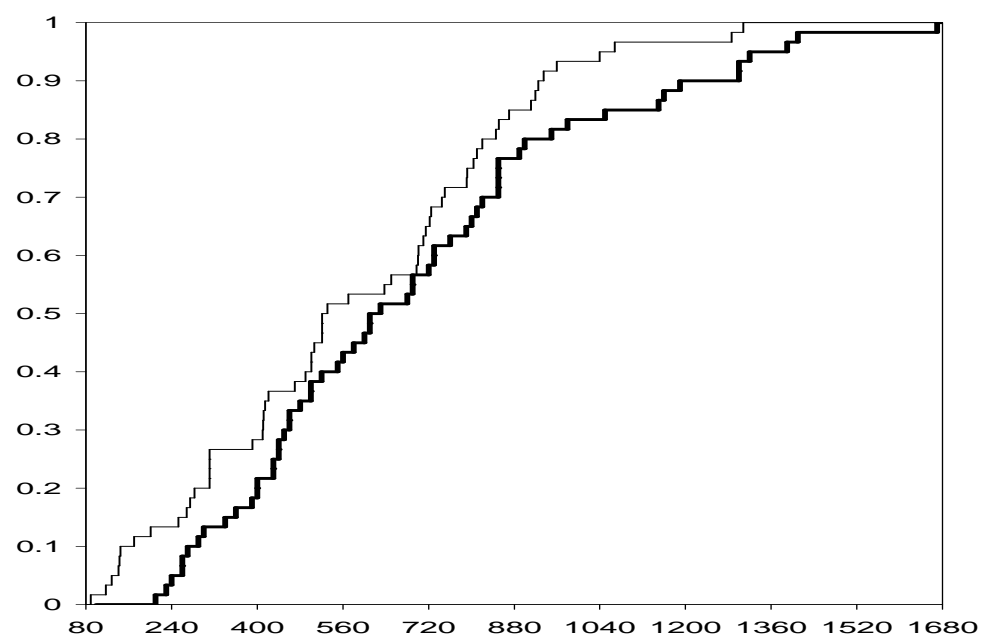

Figure 1: The cumulative distribution of observed revenues in the simultaneous ascending auction (thin black line) and ascending right-to-choose auction (heavy black line).

$i$-th predicted revenue under the risk-neutral bidding model for the given induced values. Define $\delta^{S A}$ analogously for the SA auction. The means (standard deviation) of $\delta^{A R T C}$ and $\delta^{S A}$ are $\mu_{A R T C}=138(107)$ and $\mu_{S A}=23(64)$ respectively. Consider the null hypothesis that $\mu_{A R T C}=\mu_{S A}$ against the alternative that $\mu_{A R T C}>\mu_{S A}$. Using a $t$-test we can reject the null hypothesis at even the $1 \%$ significance level $\left(t=7.15\right.$ with 58 degrees of freedom) ${ }^{10}$ Hence, the additional revenue generated by the A-RTC auction (beyond the risk-neutral predicted amount) is significantly greater than the extra revenue generated by the SA auction.

The fourth row of Table 2 shows that both auction formats were highly efficient. Here efficiency is defined as follows: denote realized surplus by $V_{\text {realized }}$, denote expected surplus were the items randomly allocated by $V_{\text {random }}$, and denote the efficient level of surplus by $V_{\text {optimal }}$. Efficiency is defined as

$$
\frac{V_{\text {realized }}-V_{\text {random }}}{V_{\text {optimal }}-V_{\text {random }}}
$$

This measure of efficiency uses the surplus obtained by randomly allocating the items as a

\footnotetext{
${ }^{10}$ See p. 435 of Mood, Graybill, and Boes for a description of this test. We can also reject the hypothesis that mean revenue in the $\mathrm{SA}$ auction is the same as mean revenue in the A-RTC auction. (The p-value is $.058)$.
} 
benchmark for measuring performance, and hence is more conservative than the standard efficiency measure of $V_{\text {realized }} / V_{\text {optimal }}$. The last row of Table 2 reports observed bidders' profits, and shows that the SA auction yielded higher expected profits, but also a higher variance.

\section{Results: Individual-Level Data}

In this section we use maximum likelihood techniques to estimate a common risk-aversion coefficient from the observed winning bids in the first stage of the A-RTC auction. The econometric model underlying the estimations is given by

$$
b_{i}^{o b s}=b_{i}^{p r e d}(r)+\epsilon_{i}
$$

where $\epsilon_{i}$ is a normally distributed random variable with mean zero and variance $\sigma^{2}, b_{i}^{\text {obs }}$ is the observed bid, and $b_{i}^{\text {pred }}(r)$ is the predicted bid assuming a model of constant relative risk aversion (CRRA) with bidders' utilities given by $u(x)=x^{1-r}$. As highlighted by Proposition 1, predicted bids depend on the degree of risk aversion as measured by the CRRA coefficient, $r$. The log-likelihood corresponding to this model is given by

$$
\log \mathrm{L}=-\sum_{i=1}^{n}\left(\frac{b_{i}^{\text {pred }}(r)-b_{i}^{\text {obs }}}{\sigma}\right)^{2}-n \log (\sqrt{2 \pi} \sigma)
$$

with $n$ the number of observations used in the estimation procedure.

\begin{tabular}{|c|c|c|c|}
\hline \hline Model & $r$ & $\sigma$ & $\log \mathrm{L}$ \\
\hline Risk Neutral & 0 & $107.8(7.0)$ & -731.9 \\
Risk Averse & $0.61(0.04)$ & $69.9(4.5)$ & -679.8 \\
\hline \hline
\end{tabular}

Table 3: Maximum likelihood estimates (standard errors in parentheses).

By maximizing the log-likelihood with respect to $r$ and $\sigma$ we obtain estimates for the risk-aversion model, see the second row of Table 3. The estimated risk aversion coefficient 
shows that bidders have the utility function $u(x)=x^{39}$. We compare the risk averse model with the risk-neutral model for which the risk aversion coefficient is fixed $r=0$ (see Table 3). Obviously, the introduction of the single risk aversion coefficient results in a significant increase in likelihood.

It is interesting to use the parameter estimates of the risk aversion model to predict revenues for the values actually employed in the experiment. Figure 2 shows observed and predicted cumulative revenue distributions, both for the risk-averse and the risk-neutral model, for the two auction formats. The null hypothesis that the observed revenues are generated by the risk averse model cannot be rejected at the $10 \%$ significance level, using a standard Kolmogorov-Smirnov test. ${ }^{11}$

\section{Conclusions}

This paper develops a simple model of the ascending right to choose (A-RTC) auction. It shows that when bidders are risk averse, selling items via an ascending right to choose auction raises more revenue than would be obtained by selling the items in simultaneous ascending (SA) auction. If bidders are risk neutral, both formats raise the same revenue. Our experimental results clearly demonstrate that the ascending right to choose auction raises significantly more revenue than the simultaneous ascending auction.

One extension is to consider bidders who value more than one item. It is an open question whether the revenue superiority of the ascending right to choose auction extends to richer valuation structures where the simultaneous ascending auction has proven to perform well (e.g. Plott and Salmon, 2003). It would also be interesting to model and experimentally assess the revenue properties of alternative right to choose auctions formats, and comparing their performance to the optimal mechanism.

\footnotetext{
${ }^{11}$ The test statistic is 0.93 while the critical value for the $10 \%$ significance level is 1.22 .
} 


\section{References}

Ashenfelter, Orly and David Genesove (1992) "Testing for Price Anomalies in Real-Estate Auctions," American Economic Review, 60, 501-505.

Burguet, Roberto (1999) "Right-to-choose in Oral Auctions," working paper 439.99, Institute for Economic Analysis, Barcelona, Spain.

Burguet, Roberto (2002) "The Condominium Problem: Auctions for Substitutes," working paper, Institute for Economic Analysis, Barcelona, Spain.

Gale, Ian and D. Hausch (1994) "Bottom-Fishing and Declining Prices in Sequential Auctions," Games and Economic Behavior, 7, 318-331.

Menezes, Flavio and Paulo Monteiro (1998) "Simultaneous Pooled Auctions," Journal of Real Estate Finance and Economics, 17(6), 219-232.

Plott, Charles R. and Timothy C. Salmon (2003) "The Simultaneous, Ascending Auction: Dynamics of Price Adjustment in Experiments and in the U.K. 3G Spectrum Auction," Journal of Economic Behavior and Organization, forthcoming.

Salmon, Timothy and Michael Iachini (2003) "Risk Aversion vs. Loss Aversion in Pooled Auctions," mimeo, Florida State University. 

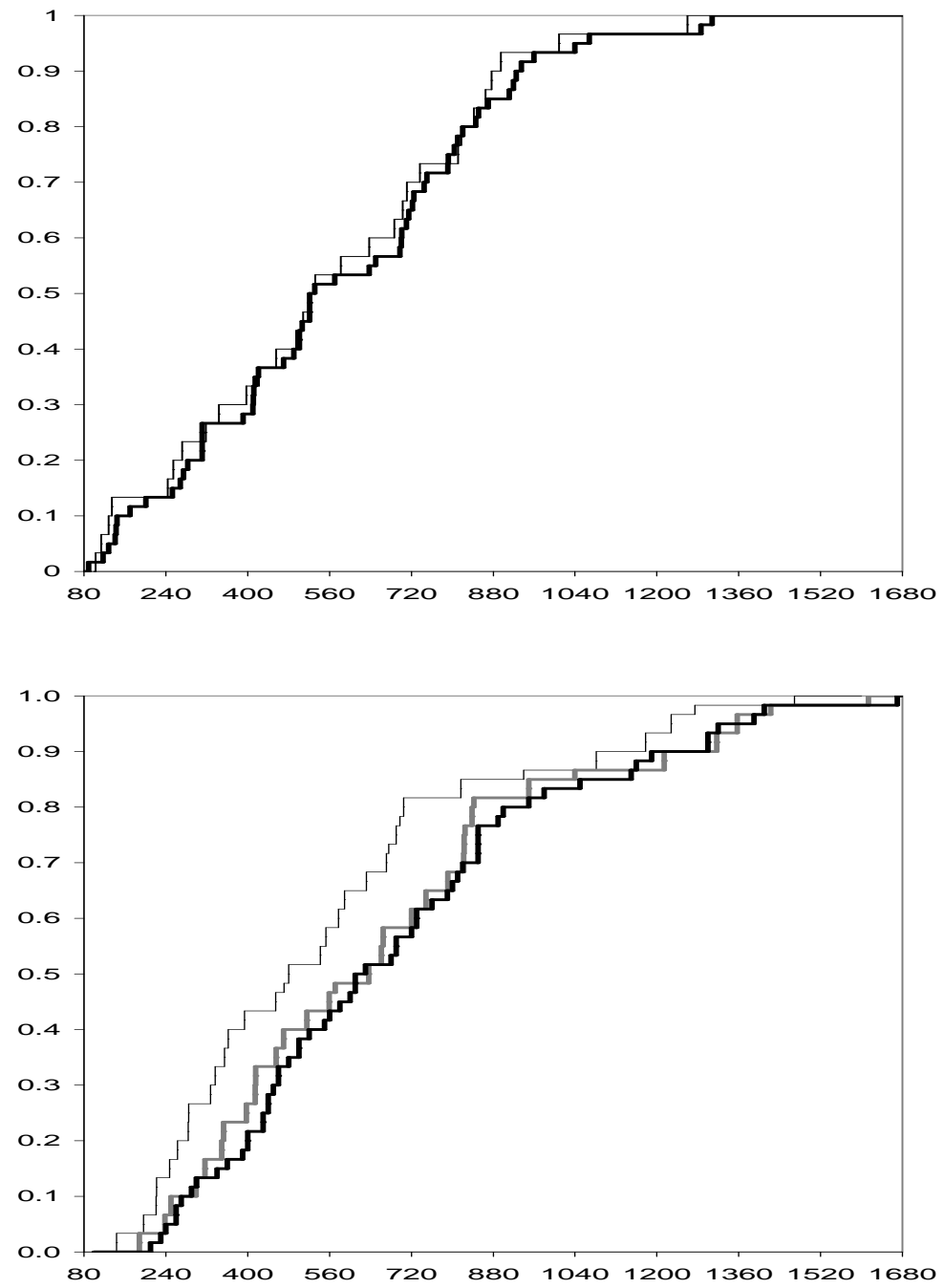

Figure 2: Predicted revenues with risk neutral bidders (thin black lines), risk averse bidders (grey lines), and observed revenues (heavy black lines) in the $S A$ auction (top) and A-RTC auction (bottom). 